\title{
Grid-connected renewables, storage and the UK electricity market ${ }^{\text {is }}$
}

\author{
I.A. Grant Wilson ${ }^{\mathrm{a}}$, Peter G. McGregor ${ }^{\mathrm{b}}$, David G. Infield ${ }^{\mathrm{c}}$, Peter J. Hall ${ }^{\mathrm{a}, *}$ \\ ${ }^{a}$ Department of Chemical and Process Engineering, University of Strathclyde, Glasgow, UK \\ ${ }^{\mathrm{b}}$ Fraser of Allander Institute, Department of Economics, University of Strathclyde, Glasgow, UK \\ ${ }^{\mathrm{c}}$ Department of Electronic E' Electrical Engineering, University of Strathclyde, Glasgow, UK
}

\section{A R T I C L E I N F O}

\section{Article history:}

Received 8 July 2010

Accepted 11 January 2011

Available online $\mathrm{xxx}$

\section{Keywords:}

Bulk electricity storage

UK electricity markets

Energy storage policy

\begin{abstract}
A B S T R A C T
This article is mainly a counterpoint to an article by Swift-Hook in the journal of Renewable Energy titled "Grid-connected intermittent renewables are the last to be stored". It also describes the four main distinct UK markets where electrical energy and services are traded, in order to provide a context for the discussion of renewable energy and energy storage in the UK electricity system. In Swift-Hook's article it was argued that "grid-connected intermittent renewables like wind energy will never be stored unless nothing else is available" and that "storage is counter-productive for fuel saving". We, however, find evidence that "grid-connected intermittent renewables" have been, and will continue to be stored when it suits the "UK market" to do so. Furthermore, Swift-Hook's article neglects the potential wider benefits that storage offers to UK energy policy's goals, in terms of reduced emissions (when used in conjunction with renewables) and enhanced security of supply.
\end{abstract}

(c) 2011 Elsevier Ltd. All rights reserved.

\section{Introduction}

In an article in this journal titled "Grid-connected intermittent renewables are the last to be stored", Swift-Hook [1] makes a number of important points relating to the "firm capacity" and the "capacity credit" of wind power, in particular, that deserve wider recognition and are well made in the article. First, is his perfectly valid argument that every energy-generating plant properly described has a "statistical chance" of being available when required, to contribute to periods of peak demand. Second, is his argument, not made for the first time, that wind power has capacity credit greater than zero. Third, is his argument that in reality "all plant has always been intermittent, including "base-load" nuclear". Indeed, we would further note, that the effect whereby the aggregated output of geographically diversified wind energy sources is less variable than a single site source, is naturally extended if the generating mix includes a wider portfolio of differing renewable resources, including wave and tidal e.g. Allan et al. [2].

However, Swift-Hook makes two apparently crucial criticisms of those who argue that storage may have a greater role to play given

\footnotetext{
The use of the word "storage" in this article is taken to mean large-scale bulk electricity storage in the $100 \mathrm{MWh}-10 \mathrm{GWh}$ range unless otherwise stated. In the UK these are exclusively pumped-hydro storage schemes at present. The use of the word "renewables" is taken to mean non-dispatchable renewable energy generation unless otherwise stated.

* Corresponding author. Tel.: +141 548 4084; fax: +141 5482539.

E-mail address: p.j.hall@strath.ac.uk (P.J. Hall).
}

an increased penetration of renewables. These arguments are firstly that "grid-connected intermittent renewables like wind energy will never be stored unless nothing else is available" and secondly that "storage is counter-productive for fuel saving". In Section 2 we consider each of these arguments in turn. In Section 3 additional reasoning is used to demonstrate that the article in question neglects and thus understates the wider potential of energy storage to contribute to meeting the agreed targets of UK energy policy. We present brief conclusions in Section 4.

\section{The Swift-Hook critique of the role of storage for renewables}

We begin by considering the argument that "renewables will never be stored unless nothing else is available", and then assess the validity of the view that storage is "counter-productive for fuel saving". However, we firstly describe the UK market framework that large-scale storage operates within.

\subsection{UK market framework}

In the UK, the British Electricity Trading and Transmission Arrangements (BETTA) determine the arrangements and methods of sale, purchase and transmission of wholesale electricity. There are presently four main distinct markets for trading physical electrical energy and services (as opposed to futures or derivatives of physical energy); the forward market, the power exchange market, the balancing mechanism market, and the ancillary services market 
that is less directly connected to the sale of electricity. The volume of electricity sold through the first three of these markets are described by the Association of Electricity Producers as over $90 \%$ through the forward market, 3\% through the power exchanges, and $2-3 \%$ through the Balancing Market [3].

The forward market is where wholesale electricity is traded using bilateral contracts between key parties; in the main the bulk generators of electricity and the "suppliers" of retail electricity to final consumers. Forward market contracts between generators and suppliers can take any form, and can be complex in nature including clauses for delivery of differing amounts of energy at different periods of the day. Each normal day is divided into 48 half hour periods with a short day (46 periods) and a long day (50 periods) caused by British summer time clock changes. Dispatchable generators can take advantage of forward contracts with time horizons for delivery varying from typically $24 \mathrm{~h}$ ahead to a year ahead. Likewise, stochastic renewable generators can also enter into long-term contracts with a "supplier" but are not likely to include clauses for delivery at a specific time of day. An example would be a contract for a supplier to take the entire output of a wind farm for a specified period, e.g. 15 years [4]. In this case the "supplier" is better able to manage the risk of imbalance within their entire portfolio, but there will be a cost penalty to the generator for the "supplier" having to shoulder the risk of potential imbalances caused by the stochastic nature of non-dispatchable renewables.

Physical information from all forward market trades relating to a particular $30 \mathrm{~min}$ period needs to be made available to the system operator before gate closure (60 min before the real-time start of that period) in order to allow the system operator (National Grid) to balance the system in real-time for the duration of the period. FPN is the term used for this information (an acronym of Final Physical Notification), and is termed "physical" due to the nature of the information i.e. the actual amount of physical energy of the trade rather than the price information associated with the trade, which is a confidential matter between the two parties to the forward trade. As mentioned above - this market accounts for over $90 \%$ of the volume of electricity traded in the UK.

The next largest market is the "power exchange" market, which allows participants to trade in more standardised electricity "products" anonymously. Typical "products" include an amount of energy to be delivered during one 30-min period, and also over 2 and $4 \mathrm{~h}$ "blocks", and take a simpler standardised form to aid liquidity and trade within the market. The electronic trade matching services provided by power exchanges can be viewed as the market of last resort, where imbalanced contractual positions on the forward market may be brought back to balance before gate closure, by buying or selling "products" anonymously through the exchanges. Stochastic renewables traded in this market are selflimited to "products" that have time horizons for delivery that can be forecast with a reasonable degree of accuracy, namely days to hours ahead. The "products" are also subject to FPN regulations, and so can also only be traded before gate closure. In addition to the physical information, a weighted average price of the "products" is also calculated by the power exchange, and provides the market index data price for electricity for the particular period. The market index data price has a bearing on the prices in the other markets and is often referred to as the "spot market" price. This market accounts for $3 \%$ of the volume of electricity traded in the UK.

The third market is the balancing mechanism market which is conducted by the system operator in order to balance the network in real-time. Generators and suppliers (purchasers) of electrical energy provide bids, in order to decrease generation or increase demand, and to provide offers, in order to increase generation or decrease demand. These bids and offers are complex and include information such as the amount and price of energy to be added to or taken from the network, and also various technical parameters regarding the speed at which the generation or demand can be varied. The system operator compares FPNs to its forecasted system demand and accepts bids and offers to physically balance the system during the period. The 60 -min window between gate closure and the start of the $30 \mathrm{~min}$ period allows the system operator to evaluate bids/offers not only on price but also by considering network constraints and the technical limits of the bid or offer e.g. how quickly can a generator ramp up or down output during the forecasted imbalance. At the end of the period the balancing and settlement code company (Elexon) uses metered data to calculate the physical imbalances of the parties that had submitted a final physical notification for a particular 30-min period. The physical imbalances take into account deviations due to bids/offers accepted by the system operator through the balancing mechanism market. Ex post "system buy prices" and "system sell prices" are calculated and form a basis with which to eventually pass on the costs of correcting the imbalance to those parties that have caused the imbalance. The eventual settlement prices are intended to encourage parties to limit the size of their imbalances. National Grid can be viewed as being responsible for physically balancing the system in real-time using the balancing mechanism market, whereas Elexon can be viewed as being responsible for the ex post settlement of the costs of the real-time balancing to the parties that caused the imbalance [5].

The ancillary services market forms a fourth distinct market from the forward market, the power exchange market and the balancing mechanism market. The UK system operator purchases several differing types of ancillary services in order to cope with unexpected circumstances, and in order to keep the network frequency and voltage within statutory limits in real-time. These services include frequency response, reserve services (over differing timeframes), reactive power, maximum generation, generation curtailment, and black start capacity [6].

Within this UK market framework it is indeed logical to suggest, as Swift-Hook does, that the most expensive electricity is likely to be the last to be accepted in the market, and also likely to be the first to be declined when demand falls. Also, his assertion that charging of a storage device adds to the overall system demand at that immediate time, and therefore adds to the amount of system fuel required at that immediate time is also strictly true. He is also correct to state that stored energy will inevitably suffer from a round-trip efficiency loss, which indeed means that the amount of energy returned to the system will always be less than the energy taken from the system.

\subsection{Renewables are the last to be stored}

However, due to the nature of the UK electricity markets, we do not believe that it is correct to state that "grid-connected intermittent renewables like wind energy will never be stored unless nothing else is available" or even, as the title of the article suggests, "renewables are the last to be stored". Any potential storage operator would be at liberty to negotiate a forward contract with a renewable generator to purchase any agreed amount of the generator's output, in which case renewable energy would be stored. It does not seem logical to suppose that storage operators would deprive themselves of increased profits by excluding a range of potentially lower marginal cost generators. If, on the other hand, the renewable generation is traded through the power exchange market, the renewable generator's price is likely to be less than that of fuel-based generation due to it's lower marginal cost, and so is likely to be the first to be traded. As the power exchange allows anonymity between parties to a trade, the renewable generator and 
storage operator would be unaware of whom they are trading with. If storage operators buy through the power exchanges, and renewable generators sell through power exchanges, it seems inevitable that as storage operators are seeking the cheapest electricity, and as renewable generators are likely to be selling the cheapest electricity, then there is a high probability that renewable energy will "not be the last to be stored".

The relationship between storage charging, wind output and market index data is explored with the following diagrams using historic data from the 4th of November to 31st December 2009 [7,8].

Fig. 1 shows the UK network pumped storage charging load and wind generation in units of power (MW) for the 48 periods per day from 00:00 on the 4th of November 2009 to 24:00 on the 31st of December 2009. It can be seen from this figure that during this period, storage charging happens each and every day regardless of the output of wind generation. However, it should be noted that the values for wind are aggregated from differing wind generators, and due to the anonymity afforded by the market structures, it is not possible to determine how much wind energy may actually be stored in a given period. We therefore believe it is incorrect to suggest as Swift-Hook does, that "grid-connected intermittent renewables like wind energy will never be stored unless nothing else is available", or indeed "the last to be stored" as these statements imply a degree of certainty, which the market data does not seem to support.

Fig. 2 shows a scatter plot of pumped storage charging and discharging loads (in units of power) against the market index price (in units of $£ / \mathrm{MWh}$ ) for each period over the same timeframe as Fig. 1. The data points with values less than 17.5 MW of either storage charging or discharging have been removed from this figure to improve clarity. It is thought that the low values represent the operational load of the storage facilities as opposed to the charging load, or periods with little or no discharging. On the $x$-axis it can be inferred from this diagram that storage charging loads are broadly clustered at a higher value than that of storage discharging loads. Furthermore, on the $y$-axis it can be inferred that the charging price is broadly clustered at a lower market index price than that of discharging, as it is profitable to sell the energy at a higher price than it was bought.

Charging trend line $y=-0.0026 x+30.562, R^{2}=0.2254$, observations $=1086, \mathrm{x}$-coefficient t-stat $=-17.76$, intercept $\mathrm{t}$ stat $=126.96$.
Discharging trend line $y=0.0171 x+27.522, R^{2}=0.4845$, observations $=1751$, x-coefficient t-stat $=40.54$, intercept tstat $=81.51$.

We believe that in the UK's market structure renewable energy generation has been and will continue to be stored when it profits storage operators to do so. It is a "market decision", and, if increased renewable generation leads to greater diurnal price variability, it is expected that storage operators would take advantage of this.

\subsection{Storage is counter-productive for fuel saving}

Swift-Hook's statement that "storage is counter-productive for fuel saving" seems to be based on only one side of the storage equation; the charging. The other side of the storage equation is how much fuel is saved when the storage facility is discharged. If it is assumed that all diurnal time-shifting storage takes place through a power exchange then the additional fuels required to meet the extra demand created by charging storage are likely to be from more efficient generating plant, as the storage operator is not likely to store energy from less efficient plant, due to its higher cost. This stored energy is then likely to be sold back at a time when the power exchange market prices are more expensive, e.g. when the marginal price is set by less efficient plant. This ability of storage to time-shift the electricity generated by more efficient plant to offset the electricity generated by less efficient plant could indeed lead to overall fuel savings - it depends on the efficiencies of the various generating plants and storage devices. It is not therefore valid to argue using only one side of this argument i.e. that storing renewable energy will lead to an increase in fuels to match the immediate demand, without also considering the other half of the fuel saving equation, which is the fuel saved by using the stored energy at a later time.

Swift-Hook also does not consider the potential fuel-increases associated with starting-up or shutting down various generating plant. Adding to the amount of start-ups and shut downs not only increases fuel use but also requires more plant maintenance. Plant operators may wish to keep a plant running in the short term, even if it is unprofitable, in order that the plant is available at a future time when it is expected to be profitable. Charging storage does increase the immediate overall demand, but can allow plants to remain generating (possibly at a lower reduced output), rather than having to be shut down. In addition to offsetting less efficient plant

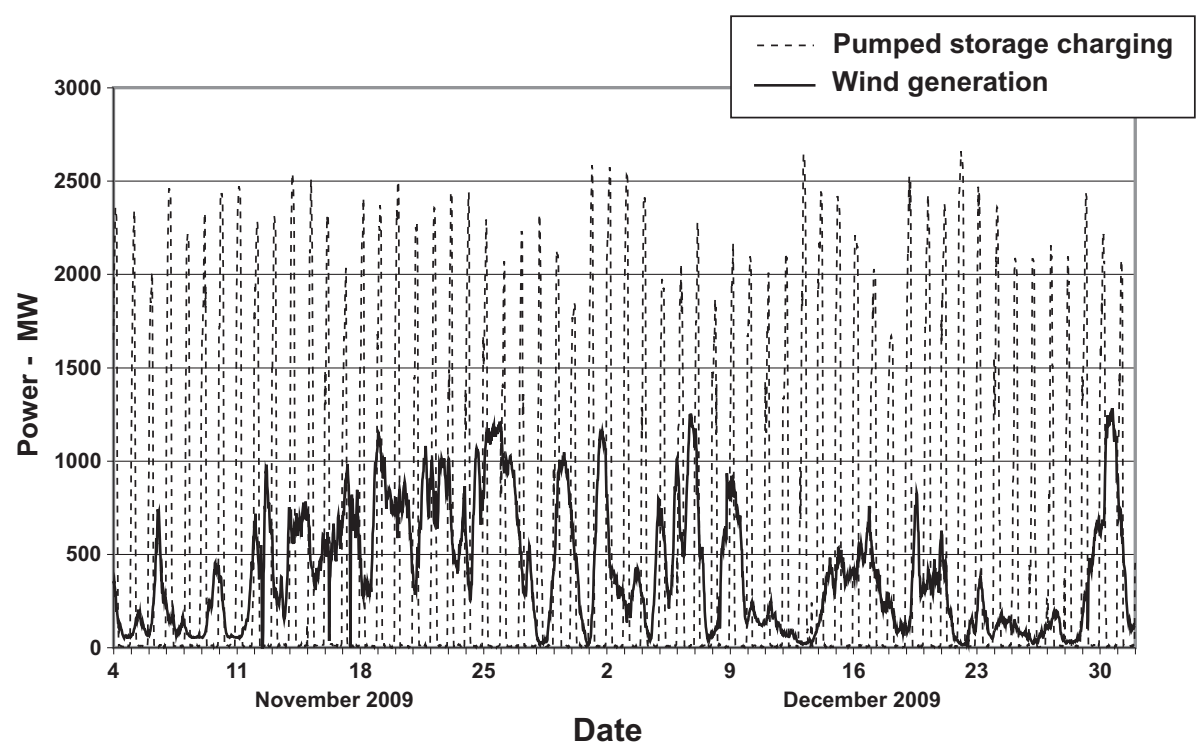

Fig. 1. UK pumped storage charging power and wind generation output. 4th Nov to 31st Dec 2009:48 periods per day. 


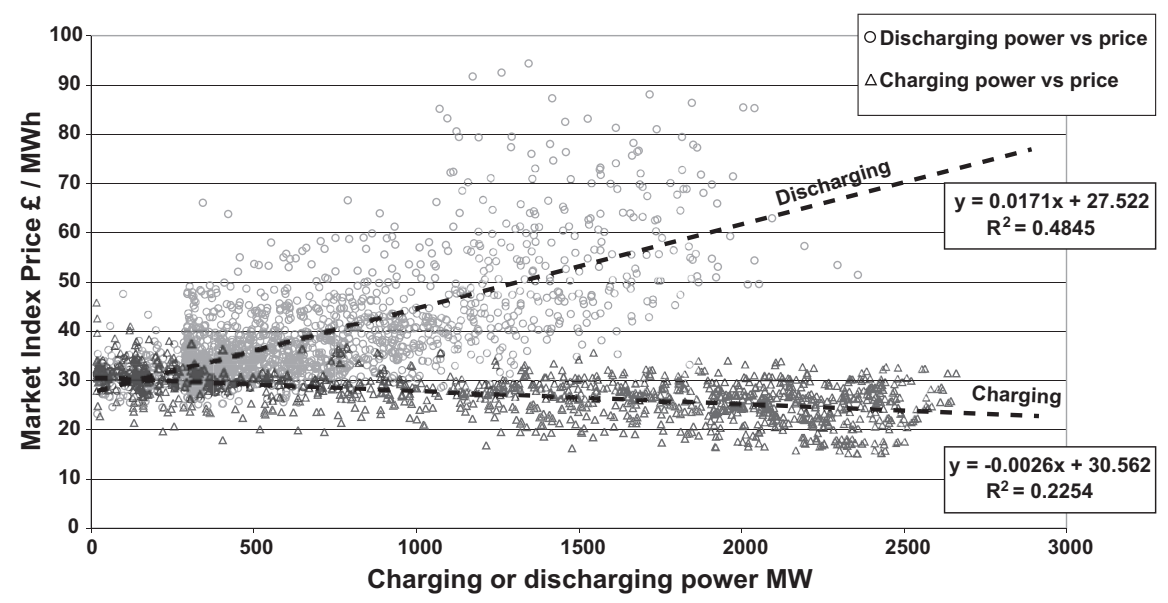

Fig. 2. UK Pumped storage charging and discharging power versus Market Index Data price. 4th Nov to 31st Dec 2009:48 periods per day.

at a future time (as mentioned above), there would certainly be fuel saving resulting from the reduction in the overall plant start-ups and shut down events facilitated by the energy storage system. Indeed this aspect of bulk electricity storage in the context of wind energy generation is far from new; early research highlighted this role [9].

The defining characteristic of storage in an electricity system is precisely that it allows some deviation between the instantaneous demand for electricity and instantaneous supply. Storage allows for the possibility of inter-temporal substitution of electricity supply: storing electricity when market prices are low; supplying electricity when prices are high. The incentive to private market participants to provide bulk-storage capacity for time-shifting is precisely the ability to take advantage of differences in the price of electricity in different periods. The ongoing use of UK storage for diurnal time shifting, in the context of significant diurnal price variations, demonstrates the strength of this (Fig. 2).

Of course, Swift-Hook is correct that there are round-trip losses of energy involved in storage, but this, in itself, does not imply that "having saved fuel in producing electricity, it makes no sense at all to store it". The mere existence of round-trip losses of energy clearly does not imply that it is never "sensible" to store energy, and there are at least potential financial benefits from doing so.

But Swift-Hook's argument is couched in terms of fuel saving, not in terms of the economics of storage. If the objective of the system were to be to substitute the largest amount of fuel then storage may appear at first glance to be sub-optimal. However, renewables generation can only actually substitute for fuel when fuel-based generation technologies are being operated. If in the future the supply of renewable energy is greater than demand for a particular market period, then further fuel substitution could only conceivably take place at a future market period when demand is greater than renewable energy supply i.e. at a time when fuel is actually being used. In this context, storage is a clear means by which (future) fuel use can in effect ultimately be substituted by (present) renewable generation.

However, "fuel substitution" is not an explicit stated goal of energy policy, although it may be considered implicit. We turn next to consider the stated goals of energy policy, and the possible contribution of storage to them.

\section{Wider energy policy considerations}

The Energy White Paper: Meeting the Energy Challenge [10] states two long-term energy challenges for the United Kingdom.
- Tackling climate change by reducing carbon dioxide emissions both within the UK and abroad; and

- Ensuring secure, clean and affordable energy as we become increasingly dependent on imported fuel.

And describes energy policy goals inter alia:

1. To put ourselves on a path to cutting the UK's carbon dioxide emissions - the main contributor to global warming - by some $60 \%$ by about 2050 , with real progress by 2020 ; (the level of $60 \%$ has subsequently been raised to $80 \%$ by the Climate Change Act 2008 (c.27)) [11].

2. To maintain the reliability of energy supplies;

We first consider how large-scale storage capacity might impact on these goals, and then discuss whether there is any case for government intervention to support its development.

The impact of the availability of storage capacity in the UK electricity system on emissions is naturally going to depend to a large degree on the storage technology, and the use to which it is put (for a comprehensive view of storage applications see Eyer and Corey [12]). However, if renewables output is stored in periods of low demand and then supplied to the market in periods of high demand, storage could potentially reduce emissions by substituting for future fossil-fuel based electricity generation, and market forces, as we have noted, move in the right direction to encourage such substitution. Furthermore, the greater the penetration of nondispatchable renewable generation requires a greater need to invest in supply and especially demand flexibility, ceteris paribus, to accommodate the variability of renewables output, although in an integrated system what matters here is variability of the aggregation of renewables output, not that of individual technologies or sites. This increased flexibility of energy systems is seen as a critical part in the transition to low-carbon energy systems. Storage could form one part of the solution to increase flexibility, but there are many others including demand side management, and also the relocation of energy to differing energy carriers e.g. electrical energy to heat or fuel [13]. It is important that differing methods of providing flexibility are viewed as complementary rather than competitive, in order to promote lower-carbon energy networks.

Of course, the incentive to invest in storage capacity in the UK is also going to be related to the ease with which electricity can be imported to and exported from the UK, and hence the degree of integration with the EU and elsewhere. A link of sufficient scale to Norway, for example, would give access to its hydro capacity, and 
a link of sufficient scale to European markets would increase the UK market's effective size. Nonetheless, there seems little doubt that storage capacity in the UK could, in principle at least, and in conjunction with renewables generation, be used to reduce UK emissions.

Storage also offers potential benefits in terms of security of supply, irrespective of the source of energy. One of the main reasons that the largest UK storage facility, the Dinorwig hydropumped storage station (with a nominal capacity $\sim 10 \mathrm{GWh}$ ), was originally built was to provide a rapid response in the event that a nuclear power plant was quickly taken off-line. The ability of storage to not only supply energy to a network, but also to take energy from a network provides additional stability to a network that is greater than an equivalent sized generator alone can provide.

However, due to the orders of magnitude difference between existing levels of pumped-hydro storage in the UK and the energy content contained within fossil fuel stocks, "storage" in terms of fossil fuel stocks will continue to be seen as the dominant factor in a strategy to improve security of supply [14]. For example, the EU mandates minimum reserves of petroleum products, and the UK has recently invested in a significant expansion in gas storage. Storage of fuels provides an insurance policy against sudden shocks to supply or demand.

Finally, the decarbonisation of transport systems globally is seen as a method for the rapid decarbonisation of the energy system as a whole. Electrification of transport would provide an additional demand on the electrical network, which could be favourable in terms of flexibility and resilience, dependent on how the extra demand is integrated. Indeed, the potentially large increase of peak demands from electrical vehicles on the distribution grid is an area of concern that is being actively researched e.g. Perujo [15]. Embedded smaller scale storage throughout the distribution network may well form part of the solution to managing distribution network demands to increase the resilience of the system.

Storage per se is historically costly, and many storage technologies are currently far from commercial viability. However, to the extent that storage can, in principle, contribute to reducing emissions and enhancing security of supply, there may be a case for government support. As for renewables, this could take the form of legally binding targets (as applied in the case of EU oil reserves), the equivalent of a ROC or Feed In Tariff based on supplies to the grid from stored renewable generation.

\section{Conclusions}

Swift-Hook's article [1] makes a number of important points about firm power and capacity credits for renewables. However, his statements that "grid-connected intermittent renewables like wind energy will never be stored unless nothing else is available" is not valid and his statement "storage is counter-productive for fuel saving" is based on a selective interpretation and is least convincing when there is significant renewables penetration. Furthermore, Swift-Hook neglects the potential wider benefits that storage offers to UK energy policy's goals, in terms of reduced emissions (when used in conjunction with renewables) and enhanced security of supply.
We have suggested that market forces are likely to operate in the "right" direction to encourage storage to take advantage of the inter-temporal distribution of electricity prices. However, it seems clear that many storage technologies are not yet approaching commercial viability. It is at least worth exploring the case for government support for storage technologies given their potential to generate wider social benefits (security of supply) and lower social costs (emissions), on the same grounds - of stimulating innovation and moving down learning curves - that are advanced to justify support for new renewable technologies. However, any case for intervention should ultimately be based on a thorough life cycle and cost-benefit analysis of storage technologies. The impact that a greater penetration of stochastic renewables may have on future price variability is a topic that requires further research, as this will have a direct impact on the profitability of bulk-storage technologies.

\section{Acknowledgements}

This work was supported by the EPSRC Supergen Energy Storage programme under grant reference EP/D031672/1, by the EPSRC Supergen Marine Consortium under grant reference EP/E040136/1, and by Techniques for Electric Power Systems with High Penetrations of Renewable Non-Thermal Generation EP/G013616/1.

\section{References}

[1] Swift-Hook DT. Grid-connected intermittent renewables are the last to be stored. Renewable Energy 2010;35(9):1967-9.

[2] Allan G, Eromenko I, McGregor PG, Swales K. The regional electricity generation mix in Scotland: a portfolio selection approach. working papers 10-10. URL. University of Strathclyde Business School, Department of Economics, http://www.strath.ac.uk/media/departments/economics/ researchdiscussionpapers/2010/10-10_final.pdf; 2010 [accessed 10.06.10].

[3] Association of Electricity Producers website. URL, http://www.aepuk.com/ about-electricity/electricity-market/; 2010 [accessed 10.06.10.

[4] Scottish Power press release. URL, http://www.scottishpower.com/ PressReleases_632.htm; 2006 [accessed 10.06.10].

[5] Elexon website. URL, http://www.elexon.co.uk/documents/publications/ guidance_notes_-_operating_within_the_bsc_arrangements,_market_entry_ and_exit_/eta_beginners_guide.pdf; 2010 [accessed 10.06.10].

[6] National Grid website. URL, http://www.nationalgrid.com/uk/Electricity/ Balancing/services/; 2010 [accessed 10.06.10].

[7] BM Reports website for historic pumped storage power data. URL, http:// www.bmreports.com/bsp/bsp_home.htm; 2010 [accessed 10.06.10].

[8] Elexon website for historic market index data prices. URL, https://www. bsccentralservices.com/index.php/home/; 2010 [accessed 03.02.11].

[9] Infield DG. Study of electricity storage and central electricity generation, Rutherford Appleton Laboratory Report. URL, http://epubs.cclrc.ac.uk/workdetails?w=50349; 1984 [accessed 01.07.10].

[10] Energy white paper: meeting the energy challenge. TSO (The Stationary Office), ISBN 9780101712422; 2007. p. 6.

[11] Climate change act 2008. TSO (The Stationary Office), ISBN 9780105427087; 2008 [chapter 27] p. 1.

[12] Eyer J, Corey G. Energy storage for the electricity grid: benefits and market potential assessment guide. URL. Sandia National Laboratories (SAND2010-0815), http://prod.sandia.gov/techlib/access-control.cgi/2010/ 100815.pdf; 2010 [accessed 01.07.10].

[13] Blarke MB, Lund $\mathrm{H}$. The effectiveness of storage and relocation options in renewable energy systems. Renewable Energy 2008;38(7):1499-507.

[14] Wilson IAG, McGregor PG, Hall PJ. Energy storage in the UK electrical network: estimation of the scale and review of technology options. Energy Policy 2010;38(8):4099-106.

[15] Perujo A, Ciuffo B. The introduction of electric vehicles in the private fleet: potential impact on the electric supply system and on the environment. A case study for the province of Milan, Italy. Energy Policy 2010;38(8):4549-61. 